\title{
Is Gonadal Therapy a Promoter of Breast Cancer? Incidence of Breast Cancer in a Cohort of Survivors of Oncological Diseases Treated with Gonadal Steroids
}

\author{
Daniela Dias $^{a} \quad$ Susana Esteves ${ }^{b}$ Sónia Andrade ${ }^{a} \quad$ Joana Maciela \\ Daniela Cavaco $^{a}$ Joana Simões-Pereira ${ }^{a}$ Maria Conceição Pereira ${ }^{a}$ \\ aEndocrinology Department, Portuguese Cancer Institute of Lisbon, Lisbon, Portugal; \\ ${ }^{b}$ Clinical Research Department, Portuguese Cancer Institute of Lisbon, Lisbon, Portugal
}

\author{
Keywords \\ Breast cancer · Oncological survivors · Hormonal replacement therapy
}

\begin{abstract}
There is a great controversy about hormonal replacement therapy in women among the members of the scientific community. Cancer survivors have sometimes had their ovary function totally or partially destroyed, thus affecting their development and quality of life. In this study, we were looking for adverse effects caused, eventually, by estroprogestative therapy in a cohort of supplemented survivors. The occurrence of breast cancer was our main concern. Ours is a retrospective study based on the clinical records of 174 survivors of several cancer diseases. Their median ages within each of the following time frames were: diagnosis -22 years old; start of endocrine treatment - 26 years old, and duration of treatment -12 years old. Evaluation was composed of breast cancer assessment, osteopenia and osteoporosis incidence, and vascular events. We have found a very low incidence of breast cancer as well as of vascular events. After treatment, a high percentage of our sample displayed bone mass improvement.

(C) 2020 The Author(s).

Published by S. Karger AG, Basel
\end{abstract}

\section{Introduction}

Throughout the past 20 years, there has been a wide controversy concerning female hormone replacement therapy (HRT). The great enemies of the HRT procedure have been breast cancer, coronary disease, strokes, and thromboembolic events. Since the discovery of estradiol by Alfred Butenandt in 1929, the concept of its use in menopause treatment has undergone periods of both enthusiasm and concern [1]. This is because, until now, the mech- 
Dias et al.: Is Gonadal Therapy a Promoter of Breast Cancer?

anisms underlying the formation of hormone-sensitive tumors are not well defined nor understood [2]. In the reviewed scientific literature, we find a number of authors arguing both against and for this specific treatment. The former are the authors of the Women Health Initiative (WHI), who have found a higher incidence of breast cancer in women treated with HRT [3], having also found thromboembolic events estimated to occur twice as much in this group than in the general population. The latter are composed of several groups of authors whose papers point to the benefits of HRT, such as the KEEPS study [4], which found a significant decrease in calcium in the vessels of treated women. Another of these studies, the DOPS (Danish Osteoporosis Prevention Study), involved 2,000 women who had begun therapy immediately after starting menopause. This study found a lower incidence of strokes, cardiac insufficiency, and myocardial ischemic events in the treated group when compared with the nontreated group. Curiously, more breast cancers were found in this last group [5]. Furthermore, Venetkoski et al. [6] showed a higher occurrence of cardiac events and death by stroke among women (432,775 patients) under 60 years of age, in the first year following discontinuation of postmenopausal therapy. In addition, Sanghvi [unpublished data] described improvement of cardiac function and structure in women on this hormonal therapy. Regarding bone health, it has been considered that hormonal therapy can prevent fractures and osteoporosis in the youngest menopausal women even when they do not display any symptoms. This is a recommendation of the Menopause North American Society's guidelines (2012 and 2017) [7]. Karim et al. [8] studied 80,955 women (after the 2002 WHI publication) who had been followed for 6.5 years and found an increase in hip fractures in the nontreated group when compared with women who had maintained therapy. Moreover, concerning dementia, some papers have found benefits of this treatment to the brain, such as the Cache County prospective study, which analyzed 5,677 women and found a correlation between a lower risk of Alzheimer's disease and this hormonal therapy, especially when medication was taken for more than 10 years [9]. The same was described by Herrera et al. [10]. Beneventi et al. [11] stressed the importance of keeping in mind the negative long-time effects of female hormone absence, namely regarding vaginal dryness, urinary tract infections and dyspareunia. Concerning cancer survival, Angioli et al. [12] and Beneventi et al. [11] advocate the utilization of HRT.

We have decided to study a group of female cancer survivors, under surveillance and treatment in our endocrine late-effects clinic, using a retrospective approach. This population constitutes a very vulnerable sample, composed of women who have been treated with estrogens alone or with progestogens (HRT) during several years. Considering that this population is more prone to develop second and third tumors, Lee et al. [13] states it is of great clinical importance to measure breast cancer incidence. This was the first goal of the study. The second was to evaluate bone health and to examine if there was any improvement with therapy. Finally, the third goal was to evaluate the prevalence of vascular disease in this very fragile population with a high vascular risk. We have no knowledge of breast cancer prevalence in this population treated by HRT. Our retrospective work was intended to look for eventual connections between this particular group and HRT. We believe in the innovative character of our research in this field.

\section{Materials and Methods}

This is a retrospective study based on our clinical records. We revised 193 clinical records of women with gonadal insufficiency after chemoradiotherapy. Of these, 19 patients were excluded due to several factors: existence of active disease, previous vascular diseases and patients with less than 3 years of treatment. We have found 174 eligible processes. These 
Table 1. Clinical and demographic characterization

\begin{tabular}{lcccc}
\hline Characteristic & $\begin{array}{c}\text { All patients } \\
(n=174)\end{array}$ & $\begin{array}{c}\text { Group A } \\
(n=76)\end{array}$ & $\begin{array}{c}\text { Group B } \\
(n=69)\end{array}$ & $\begin{array}{c}\text { Group C } \\
(n=29)\end{array}$ \\
\hline Diagnosis, $n$ (\%) & & & & \\
$\quad$ Hematological diseases & $126(72)$ & $43(57)$ & $57(83)$ & $26(90)$ \\
$\quad$ Lymphoma/Hodgkin disease & $48(28)$ & $11(14)$ & $30(43)$ & $7(24)$ \\
$\quad$ Leukemia & $66(38)$ & $31(41)$ & $22(32)$ & $13(45)$ \\
$\quad$ Aplastic anemia & $6(3)$ & $1(1)$ & $4(6)$ & $1(3)$ \\
$\quad$ Multiple myeloma & $6(3)$ & 0 & $1(1)$ & $5(17)$ \\
CNS tumors & $20(11)$ & $17(22)$ & $3(4)$ & 0 \\
Ovary tumors & $5(3)$ & $4(5)$ & $1(1)$ & 0 \\
Sarcomas & $6(3)$ & $3(4)$ & $3(4)$ & 0 \\
Cavum tumors & $9(5)$ & $2(3)$ & $5(7)$ & $2(7)$ \\
Other & $8(5)$ & $7(9)$ & 0 & $1(3)$ \\
Age at diagnosis, years & $22[0-51]$ & $10.5[0-18]$ & $28[19-40]$ & $44[41-51]$ \\
$\quad$ Median [range] & & & & \\
Treatment, $n$ (\%) & $33(19)$ & $25(33)$ & $7(10)$ & $1(3)$ \\
$\quad$ Surgery & $149(86)$ & $65(86)$ & $58(84)$ & $26(90)$ \\
Chemotherapy & $88(51)$ & $49(64)$ & $30(43)$ & $9(31)$ \\
Radiotherapy & $121(70)$ & $43(57)$ & $54(78)$ & $24(83)$ \\
Bone marrow transplantation & $26(15)$ & $15(20)$ & $8(12)$ & $3(11)$ \\
$\quad$ Total body irradiation & & & & \\
\hline
\end{tabular}

women had taken female hormones for several reasons: puberty induction; restart of normal sexual development, previously interrupted for treatments or hormonal supplementation after adult gonadal lesion. All were survivors of oncological diseases and dangerous genetic hematological diseases. The cohort contained hematological diseases (126), brain tumors (20), ovary tumors (5), sarcomas (6), cavum tumors (9) and a group of very rare diseases (8). Surgery was conducted in 33 patients. Chemotherapy was applied in 149 and data on this matter was not available in 4 of the records. Radiotherapy was done in 88 patients and total body irradiation (TBI) in 26.121 patients (Table 1) had undergone bone marrow transplantation (BMT). Considering the whole sample, the median age at diagnosis was 22 years $(0-51)$, the median age at treatment start was 26 years (11-59), and the median duration of treatment was 12 years (3-36). Estrogens plus progestogens were taken by 162 patients, estrogens alone by 11 , and progestin alone by 1 (Table 2). Bone mineral density was evaluated using the DEXA scan measurement in the lumbar spine and the femoral neck. The first DEXA scan was performed after the age of 21. In cases of osteopenia (less than -1.5 SDS) or osteoporosis (less than -2.5 SDS), the exam was repeated every 2 years and calcium (1,500 $\mathrm{mg}$ a day) plus cholecalciferol (400 IU/day) supplementation was given. This strategy was readjusted every 2 years according to a new exam. Variations of more or less than 0.5 SDS were considered improvement or worsening, respectively. Vascular events were registered. For a clearer analysis, we divided the sample into three groups: group A with patients who required intervention regarding the onset or completion of puberty; group B with patients who had attained Tanner stage 5 of sexual development and in whom ovary function had been destroyed at a young age (earlier than 40); and group $\mathrm{C}$ with females aged more than 40 years who had entered premature menopause after oncological treatments. Group A included 76 patients. They were treated with gonadal steroids in a biphasic way. Initially, estradiol was given $[0.25$ $\mathrm{mg} /$ day for 2 years, the following 2 years $0.5 \mathrm{mg} /$ day, the final 2 years $1 \mathrm{mg} /$ day) to develop breast buds and a progestin was added at Tanner stage 4 for complete sexual development. Subsequent treatment included no suppressible gonadotropins, with sequential estradiol and 
Table 2. Characterization of treatment with gonadal steroids

\begin{tabular}{|c|c|c|c|c|}
\hline Characteristic & $\begin{array}{l}\text { All patients } \\
(n=174)\end{array}$ & $\begin{array}{l}\text { Group A } \\
(n=76)\end{array}$ & $\begin{array}{l}\text { Group B } \\
(n=69)\end{array}$ & $\begin{array}{l}\text { Group C } \\
(n=29)\end{array}$ \\
\hline \multicolumn{5}{|l|}{ Age treatment start, years } \\
\hline Median [range] & 26 [11-59] & 16 [11-45] & $31[21-51]$ & 46 [42-59] \\
\hline \multicolumn{5}{|l|}{ Treatment duration, years } \\
\hline Median [range] & $12[3-36]$ & $12[4-36]$ & 14 [4-27] & 10 [3-19] \\
\hline Total exposure time, patient-years & $2,282.5$ & 1,059 & 931.5 & 292 \\
\hline \multicolumn{5}{|l|}{ Drug used, $n(\%)$} \\
\hline Estrogens and progesterone & $162(93)$ & $72(95)$ & $66(96)$ & $24(83)$ \\
\hline Estrogens only & $11(6)$ & $4(5)$ & $2(3)$ & $5(17)$ \\
\hline Progesterone only & $1(1)$ & 0 & $1(1)$ & 0 \\
\hline
\end{tabular}

Table 3. Incidence rate of breast cancer - number of incident cases per 1,000 patient-years exposure to treatment with gonadal steroids

\begin{tabular}{lllll}
\hline & $\begin{array}{l}\text { Incident cases } \\
\text { of breast cancer }\end{array}$ & $\begin{array}{l}\text { Patient- } \\
\text { years }\end{array}$ & $\begin{array}{l}\text { Incidence } \\
\text { rate }\end{array}$ & $95 \% \mathrm{CI}$ \\
\hline Overall sample & 2 & $2,282.5$ & 0.88 & $0.11-3.17$ \\
& & 1,059 & 0.94 & $0.11-3.17$ \\
Group A & 1 & 931.5 & 0 & $0.02-5.26$ \\
Group B & 0 & 292 & 3.42 & $0.09-19.08$ \\
Group C & 1 & & & \\
\hline
\end{tabular}

progestin (estradiol hemihydrate $2 \mathrm{mg}$ during 12 days; norethisterone acetate $1 \mathrm{mg}$ during 10 days plus estradiol hemihydrate $2 \mathrm{mg}$ and finally only estradiol hemihydrate $1 \mathrm{mg}$ during 6 days). The median age at disease onset was 10.5 years (0-18), the median age at treatment onset was 16 years (11-18), and the median duration of treatment in group A patients was 12 years (4-36) (Tables 1 and 2). Group B included 69 patients. This group had also taken gonadal steroids. The median age at diagnostic was 28 years (19-40). The median age at therapy onset was 31 years (21-40), and the median duration of treatment was 14 years (4-27). Treatment consisted of combined estradiol ( $1 \mathrm{mg} /$ day) and a progestin pill $(0.5 \mathrm{mg} /$ day) or patch (estradiol $50 \mu \mathrm{g} /$ day alone or combined with levonorgestrel $7 \mu \mathrm{g} /$ day) (Tables 1, 2). Group C included 29 patients. All of them had entered menopause after the age of 40. They were also treated with estradiol and progestin pills or patches at the same dosage as group B and were administered estradiol only in cases without a uterus. After the age of 50, treatment dosage was reduced to $50 \%$. The median age at diagnosis was 44 years (41-51) and the median age at treatment onset was 46 years (42-59). They underwent treatment during a median period of 10 years (3-19). All data concerning this cohort is explained in Tables 1 and 2 . After the age of 25, all patients undertook a mammary echography and later, after the age of 35, a mammography. The frequency of these exams was determined according to patient age. Gynecological echography was done only after the age of 20 and was repeated if any abnormality was found, for instance, myoma of the uterus or ovary cyst. Statistical analysis was done conducting a descriptive analysis for clinical, demographic and treatment characterization using the median and range for quantitative variables and the absolute and relative frequencies for categorical variables. The incidence of breast cancer and of cardiovascular adverse events (thrombosis, stroke and myocardial infarction) was calculated by dividing the number of observed events by the total patient-years of exposure to gonadal steroids, and 95\% confidence intervals were calculated using the exact method. Data analysis was performed using statistical software. 
Dias et al.: Is Gonadal Therapy a Promoter of Breast Cancer?

Table 4. Densitometry characterization at baseline and calcium and cholecalciferol supplementation

\begin{tabular}{lcccc}
\hline & $\begin{array}{c}\text { All patients } \\
(n=174)\end{array}$ & $\begin{array}{c}\text { Group A } \\
(n=76)\end{array}$ & $\begin{array}{c}\text { Group B } \\
(n=69)\end{array}$ & $\begin{array}{c}\text { Group C } \\
(n=29)\end{array}$ \\
\hline $\begin{array}{l}\text { First evaluation, } n(\%) \\
\quad \text { Lumbar spine }\end{array}$ & & & \\
$\quad$ Normal & $98(56)$ & $37(49)$ & $45(65)$ & $16(55)$ \\
$\quad$ Osteopenia & $35(20)$ & $15(20)$ & $15(22)$ & $5(17)$ \\
$\quad$ Osteoporosis & $18(10)$ & $9(12)$ & $3(4)$ & $6(21)$ \\
$\quad$ Unknown/not available & $23(13)$ & $15(20)$ & $6(9)$ & $2(8)$ \\
Femoral neck & & & & \\
$\quad$ Normal & $104(60)$ & $41(54)$ & $47(68)$ & $16(55)$ \\
$\quad$ Osteopenia & $33(19)$ & $11(14)$ & $13(19)$ & $9(31)$ \\
$\quad$ Osteoporosis & $8(5)$ & $5(7)$ & $1(1)$ & $2(7)$ \\
$\quad$ Unknown/not available & $29(17)$ & $19(25)$ & $8(12)$ & $2(7)$ \\
Calcium/cholecalciferol supplementation, $n(\%)$ & $73(42)$ & $30(39)$ & $31(45)$ & $12(41)$ \\
\hline
\end{tabular}

\section{Results}

The more prevalent symptoms found in the whole sample were flushes (57.65\%) and dyspareunia (8.16\%). After 1 month of treatment, flushes disappeared but dyspareunia did not, having needed around 6 months to vanish.

\section{Breast Cancer and Bone Health}

Group A

All patients attained Tanner stage 5. In this group, there was one patient with breast cancer. The diagnosis was conducted on a 37-year-old patient during her twenty-fourth year of therapy. This patient had had a myeloblastic acute leukemia at age 12 and had been submitted to conventional chemotherapy and BMT with previous ablative chemotherapy (busulfan, cyclophosphamide) and TBI (12 Gy) as a conditioning regime. She had had one spontaneous menstrual cycle before the illness and, upon starting hormonal therapy, at age 13, she had an LH level of $49 \mathrm{mIU} / \mathrm{mL}$ and FSH of $42.9 \mathrm{mIU} / \mathrm{mL}(\mathrm{NV}<15)$. The breast tumor was intraductal with positive receptors for E2 (85\%), Prog (85\%), ErbB+ and Ki67 (30\%). She is alive and, after surgery and chemotherapy, has been disease-free for the past 4 years. This occurrence represents an incidence rate of $0.94 / 1,000$ patient-years of exposure to treatment (Table 3). In this group, lumbar/femoral osteopenia was found in $20 \% / 14 \%$ of patients and osteoporosis in $12 \% / 7 \%$. Treatment improvement was achieved in 38\%/31\% at lumbar and femoral points, respectively (Tables 4-6).

\section{Group B}

We have not found any case of breast cancer in this patient subgroup. Regarding bone density, lumbar/femoral osteopenia was found in $22 \% / 19 \%$ and osteoporosis in $4 \% / 1 \%$ of patients. Treatment improvement was achieved in 50\%/57\% at lumbar and femoral points, respectively (Tables 4-6).

\section{Group C}

One patient developed breast cancer in this subgroup. At 51 years of age, she had had a multiple myeloma and had been treated with chemotherapy. At 52 years of age, she underwent BMT with previous ablative chemotherapy (melphalan). She immediately started menopause, complaining of flushes and high gonadotropin values (LH-49.1 mIU/mL and FSH-88 $\mathrm{mIU} / \mathrm{mL}$ ). She was started on HRT and after 3 years, she was diagnosed with intraductal 
Table 5. Lumbar osteopenia/osteoporosis

\begin{tabular}{llccc}
\hline Lumbar spine & Group A & Group B & Group C & Total sample \\
\hline Benefited & $38 \%$ (9 patients) & $50 \%$ (9 patients) & $64 \%$ (7 patients) & $47 \%$ (25 patients) \\
Stabilization & $33 \%$ (8 patients) & $44 \%$ (8 patients) & $27 \%$ (3 patients) & $36 \%$ (19 patients) \\
Not evaluable & $29 \%$ (7 patients) & $6 \%$ (1 patients) & $9 \%$ (1 patients) & $17 \%$ (9 patients) \\
Total patients & $45 \%$ (24 patients) & $34 \%$ (18 patients) & $21 \%$ (11 patients) & $100 \%$ (53 patients) \\
\hline
\end{tabular}

Regarding the 53 patients with lumbar osteopenia/osteoporosis at baseline: $25 / 53$ (47.17\%) had a beneficial effect, $19 / 53$ (35.89\%) had a stabilization and in $9 / 53$ (16.98\%) the effect was not evaluable.

Table 6. Femoral osteopenia/osteoporosis

\begin{tabular}{lcccc}
\hline Femoral neck & Group A & Group B & Group C & Total sample \\
\hline Benefited & $31 \%$ (5 patients) & $57 \%$ (8 patients) & $55 \%$ (6 patients) & $46 \%(19$ patients) \\
Stabilization & $38 \%$ (6 patients) & $36 \%$ (5 patients) & $18 \%$ (2 patients) & $32 \%(13$ patients) \\
Worsening & $6 \%$ (1 patient) & $7 \%(1$ patient) & $9 \%(1$ patient) & $7 \%(3$ patients) \\
Not evaluable & $25 \%$ (4 patients) & $0 \%$ (0 patients) & $18 \%(2$ patients) & $15 \%(6$ patients) \\
Total patients & $39 \%$ (16 patients) & $34 \%$ (14 patients) & $27 \%$ (11 patients) & $100 \%$ (41 patients) \\
\hline
\end{tabular}

Regarding the 41 patients with femoral osteopenia/osteoporosis at baseline: 19/41 (46\%) had a beneficial effect, $13 / 41(32 \%)$ had a stabilization of the baseline status, 3/41 (7\%) had a worsening condition and in $6 / 41(15 \%)$ the effect was not evaluable.

breast cancer with positive receptors E2 (100\%) and ErbB+. She was submitted to surgery, radiotherapy and antiestrogen therapy and died with myeloma relapse at age 70 . This patient had a family history of breast cancer (her grandmother, grandaunt and sister). This occurrence represents an incidence rate of 3.42/1,000 patients-years of exposure to treatment (Table 3). Lumbar/femoral osteopenia was found in 17\%/31\% and osteoporosis in $21 \% / 7 \%$ of the patients. Treatment improvement was achieved in $64 \% / 55 \%$ at lumbar and femoral points, respectively (Tables 4-6).

\section{Vascular Disease}

During the follow-up, 6 vascular complications were observed, 4 of which were thrombosis occurring in areas treated with radiotherapy, and the remaining 2 were leg phlebitis (Table 7). Looking at the whole sample, we can see an incidence rate of 2.63 cases per 1,000 patients-years of exposure to treatment (Table 8).

\section{Discussion}

\section{Breast Cancer}

The scientific community knows of the high prevalence of secondary tumors in surviving cancer patients. In this population, all therapies can induce cell mutation and, consequently, increase the risk of a new primary tumor. Radiotherapy is the main oncogenic promoter, as the appearance of skin tumors in irradiated areas, as well as meningiomas, sarcomas and leukemias, is very common. De Fine Licht et al. [14] have found 182 breast cancers in 21,297 survivors of childhood cancer, which represents 47 more cases than those in their control group. Kolb et al. [15] have found 4 breast cancers in 1,036 patients who had undergone BMT. 
Dias et al.: Is Gonadal Therapy a Promoter of Breast Cancer?

Table 7. Characteristics of vascular events

\begin{tabular}{|c|c|c|c|c|c|}
\hline Diagnosis & $\begin{array}{l}\text { Age at } \\
\text { diagnosis, } \\
\text { years }\end{array}$ & $\begin{array}{l}\text { Years of gonadal } \\
\text { steroids } \\
\text { treatment }\end{array}$ & $\begin{array}{l}\text { Previous vascular } \\
\text { aggressive treatments }\end{array}$ & Gonadal steroids taken & $\begin{array}{l}\text { Vascular } \\
\text { occurrence }\end{array}$ \\
\hline \multirow[t]{3}{*}{ Suprasellar germinoma } & \multirow[t]{3}{*}{12} & \multirow[t]{3}{*}{9} & \multirow[t]{3}{*}{ Skull radiotherapy 54 Gy } & Norelgestromin & \multirow{3}{*}{$\begin{array}{l}\text { Right lateral } \\
\text { brain sinus } \\
\text { thrombosis }\end{array}$} \\
\hline & & & & Estradiol & \\
\hline & & & & Ethinylestradiol & \\
\hline \multirow{2}{*}{$\begin{array}{l}\text { Acute lymphocytic } \\
\text { leukemia }\end{array}$} & \multirow[t]{2}{*}{23} & \multirow[t]{2}{*}{17} & \multirow[t]{2}{*}{ TBI } & Estradiol & \multirow[t]{2}{*}{ Leg phlebitis } \\
\hline & & & & $\begin{array}{l}\text { Gestodene } \\
\text { norethisterone }\end{array}$ & \\
\hline $\begin{array}{l}\text { Acute lymphocytic } \\
\text { leukemia }\end{array}$ & 26 & 14 & TBI & $\begin{array}{l}\text { Gestodene, desogestrel } \\
\text { ethinylestradiol }\end{array}$ & $\begin{array}{l}\text { Phlebitis in } \\
\text { varicose legs }\end{array}$ \\
\hline Multiple myeloma & 30 & 9 & $\begin{array}{l}\text { Two BMT + radiotherapy } \\
\text { on subclavian area }\end{array}$ & $\begin{array}{l}\text { Estradiol } \\
\text { norethisterone }\end{array}$ & $\begin{array}{l}\text { Vena subclavia } \\
\text { thrombosis }\end{array}$ \\
\hline \multirow[t]{4}{*}{ Cavum tumor } & \multirow[t]{4}{*}{22} & \multirow[t]{4}{*}{16} & \multirow{4}{*}{$\begin{array}{l}\text { Cavum radiotherapy and } \\
\text { cervical region }\end{array}$} & Drospirenone & \multirow{4}{*}{$\begin{array}{l}\text { Left carotid } \\
\text { thrombosis }\end{array}$} \\
\hline & & & & Norgestrel & \\
\hline & & & & Estradiol & \\
\hline & & & & Ethinylestradiol & \\
\hline \multirow[t]{2}{*}{$\begin{array}{l}\text { Acute lymphocytic } \\
\text { leukemia }\end{array}$} & \multirow[t]{2}{*}{5} & \multirow[t]{2}{*}{6} & \multirow[t]{2}{*}{$\begin{array}{l}\text { Skull radiotherapy } 24 \text { Gy } \\
\text { and medullae } 12 \text { Gy }\end{array}$} & Estradiol & \multirow[t]{2}{*}{ Leg thrombosis } \\
\hline & & & & Noresthisterone & \\
\hline
\end{tabular}

Table 8. Incidence rate of cardiovascular events

\begin{tabular}{llllr}
\hline & $\begin{array}{l}\text { Incident } \\
\text { cardiovascular } \\
\text { events, } \mathrm{n}\end{array}$ & $\begin{array}{l}\text { Patient- } \\
\text { years }\end{array}$ & $\begin{array}{l}\text { Incidence } \\
\text { rate }\end{array}$ & $95 \%$ CI \\
\hline Overall sample & 6 & $2,282.5$ & 2.63 & 0.96 to 5.72 \\
Group A & 2 & 1,059 & 1.89 & 0.23 to 6.82 \\
Group B & 4 & 931.5 & 4.29 & 1.17 to 10.99 \\
Group C & 0 & 292 & 0 & 0 to 12.63 \\
\hline
\end{tabular}

Number of incident cases per 1,000 patient-years exposure to treatment with gonadic steroids. Overall, 6 cardiovascular events were reported ( 4 thrombosis and 2 phlebitis).

Breast cancer is very frequent in individuals above the age of 50 and no one really knows its true development processes and underlying mechanisms. The genetics of breast cancer is a field in continuous evolution, but mutations have been identified in $<30 \%$ of cases with suggestive personal or family histories [16]. There are several mutations which lead to a higher risk of developing breast cancer, and estrogens can act as cell-proliferating agents and stimulate the growth of tissue in culture; however, they can also inhibit growth at high dosages [17]. Rebbeck et al. [18] showed that in women with BRCA1/2 mutations in whom bilateral prophylactic oophorectomy was performed, HRT does not negate the protective effect of bilateral prophylactic oophorectomy. These results induce us to look at the genetic nature of cancer breast appearance rather than the hormonal one. On the other hand, our population 
has been under great stress during treatment and, after the cure, the fear of relapse is another stressful factor that is always present. In certain cases, after allogeneic BMT, graft-versus-host disease requires a long process composed of a series of treatments, which are themselves stressing. Herrera et al. [10] show the action of protective estradiol in certain types of cognition, when in the presence of stress. In accordance with their point of view, some of the patients in this study who received brain radiotherapy, and are thus more prone to developing cognition deficiencies, will benefit from HRT. Furthermore, protection against vascular dementia in those receiving HRT was demonstrated by Mikkola et al. [19]. Bearing in mind the aforementioned beneficial effects, in 2018, Angioli et al. [12] published an article supporting replacement therapy in cancer survivors and Beneventi et al. [11] published one regarding BMT.

Considering our 2 cases, we identified several risk factors for breast cancer development. Regarding the first breast cancer, the patient had been submitted, at age 13, to a TBI during oncological treatment and it is known that irradiation can induce mutagenic cell transformation. According to the Harmonization Group for Breast Cancer Surveillance [20], breast cancer as a secondary tumor should be a focal concern among medical providers. While highdosage radiotherapy leads to tissue destruction, lower dosages can promote the appearance of a second tumor several years after treatment. After 24 years, the same patient, then at age 37, developed breast cancer while on HRT. It is known that TBI is responsible for the occurrence of several types of cancer, many decades later, for instance, thyroid, brain, liver, lung and, of course, breast cancer. Danylesko et al. [21] report that second malignancies after BMT occur in up to $15 \%$ of patients 15 years after treatment, with a progressive increase in incidence throughout life, being responsible for $5-10 \%$ of deaths occurring after BMT. Diagnosing second tumors is always a lengthy procedure. Demoor-Goldschmidt et al. [22] studied the occurrence of very aggressive breast cancers in 121 patients as second malignancies following radiotherapy. Only after a mean of 15 years of follow-up were second tumors diagnosed. The youngest member of the group was 38 years old when a second tumor was diagnosed. Bilateral breast cancer was diagnosed in $16 \%$ of the patients. TBI was most probably the principal promoter for the appearance of this cancer.

Regarding the second case, it is that of a 51-year-old patient with multiple myeloma, submitted to BMT, who had received HRT during 3 years. She passed away at age 70 due to a myeloma relapse. This patient had a family history of breast cancer, for which we can assume a genetic predisposition. In 2013, Naghavi [23] described a worldwide breast cancer incidence of 1.8 million, stating this as the principal type of cancer in women. Some colleagues argue in favor of HRT, even for women who previously had breast cancer, stating that it does not have any adverse impact on recurrence and mortality. This is also shown by the Collaborative Group on Hormonal Factors in Breast Cancer and the Canadian Consensus on Menopause and Osteoporosis [24]. They followed up 161,116 women during a period of 20 years, with ages ranging from 50 to 70, looked for the occurrence of breast cancer events, and showed us the following results: never used HRT45/1,000; >15 years of HRT 57/1,000; alcohol consumers (2 drinks a day) 72/1,000; weight gain 90/1,000. Espié et al. [25] prospectively studied 4,949 women and found an incidence of breast cancer superior to a nontreated group. Several authors also showed a better response of cancer cells in women previously treated with hormone therapy because cells were more differentiated. We also know that $75 \%$ of cases occur after the age of 50 . A recent paper by Roger Lobo [published online] shows that the use of gonadal steroids confers a negative risk of breast cancer; on the contrary, being a flight attendant and obesity increase the risk twice as much.

Bone Health

Scientific literature includes several publications establishing a positive relationship between gonadal steroids and bone density. Misra [26] considers the deficiency of gonadal 
steroids to be a strong cause of reduced bone mineral density in adults, and of impaired bone accrual in adolescents. The effect of hypogonadism during puberty is of particular concern. During adolescence, there is a marked increase in bone accrual which is critical for the attainment of optimal peak bone health and suitable bone remodeling. In adults, gonadal steroid deficiency not only affects remodeling but also impairs microfracture repairment. In our study population, there are also other negative factors such as chemotherapy, radiotherapy, other hormonal deficiencies, and changes in body weight and muscle mass, all of which can affect bone health. Lobo [27] reports an increase in osteoporotic fractures since the WHI. This is in accordance with women having stopped gonadal steroid intake. Wang et al. [28] studied 9,922 postmenopausal women from the WHI, after having conducted randomized trials with women with a genetic predisposition to low bone mass and fractures, and concluded that even with such a background, HRT reduces the risk of fracture in postmenopausal women. In our osteoporosis group, we find a high incidence of radiotherapy on the lumbar spine and the femoral neck among those treated with BMT. Using high doses of glucocorticoids in graft-versus-host disease is known to have a deleterious effect on bone density, and a probably more deleterious consequence in the cortical area. All groups showed a very good response to treatment but the number of patients in each group was neither sufficient for the purpose of determining statistical significance, nor for establishing correlations with calcium-cholecalciferol supplementation.

\section{Vascular Disease}

It is known that HRT must be given in low dosages aiming to alleviate symptoms such as flushes, dyspareunia, sleep disturbances and mood swings. Great benefits are obtained when therapy starts immediately after menopause. Starting it after age 60 is not recommended because therapy can cause several vascular problems. At this age, almost all women have atheromatous plaques and, as estradiol has the capacity of removing them, this may cause thromboembolic events. This line of thought equally explains why it is not recommended to consider this therapy for women who have had their menopause more than 10 years ago. They have a tremendous possibility of already having built important plaques and, being on HRT, there is a great risk of dissolving those vascular formations. Estrogens increase proinflammatory factors such as MMP-9 (matrix metalloproteinase 9), which could digest gelatin atheromatous plaque, causing instability and disruption. Among the general population between the ages of 50 and 54, cerebrovascular events (thrombosis or ischemia) have a prevalence of 3.8/10,000/year. In this same age group, a prevalence of 1-2/10,000/year was found, when under treatment. We must remember that in the gestational period the risk is $60 / 10,000$. These data were denied by the WHI study [3], which found that the risk of development of vascular thromboembolism was doubled. However, it is important to remember that they included women with previous vascular accidents. Some progesterones have a deleterious effect on the endothelium. We must avoid norpregnane derivatives (nomegestrol acetate and promegestone) and medroxyprogesterone acetate (this was taken by women from the WHI). Visceral obesity is correlated positively with vascular accidents and it was demonstrated by Papadakis et al. [29] that HRT diminishes abdominal adiposity.

\section{Conclusion}

We are convinced that HRT in women is very safe, having protective effects on cardiac tissue, bone and vascular diseases, and that it does not increase the risk of breast cancer. Our results showed a very high security margin and an improvement in the quality of life of the patients receiving HRT. The number of patients with breast cancer was very small as were 
Dias et al.: Is Gonadal Therapy a Promoter of Breast Cancer?

cases of vascular events. This is in accordance with the position statement of the North American Menopause Society [7], which says that the risk of breast cancer is rare while on gonadal steroids. This population has high levels of anxiety and depression and, as such, we cannot miss the serotonergic action that estradiol has on the brain [10], which may provide the patients with better mental health. Some sleep disturbances might ameliorate with progesterone, which has sedating effects without affecting daytime cognitive functions [7]. There are no data on the duration of therapy but, based on the effects of estrogen on vessel walls (dilatation via nitric oxide, inhibition of inflammatory processes and release of endothelin-1), Lobo [30] recommends maintaining therapy with adaptations to each individual person, while Faubion et al. [31] recommend menopause treatment maintenance at least until the physiological menopause age in patients with premature or early menopause. We will proceed with treatments while cultivating an enhanced awareness regarding this particular population, in order to obtain more data on these matters.

\section{Acknowledgments}

I would like to thank my whole team for their collaboration and support.

\section{Statement of Ethics}

This research was done under the Guidelines for Human Studies and was conducted ethically in accordance with the World Medical Association Declaration of Helsinki. It was approved by our local ethical committee and all the patients have given their written consent.

\section{Disclosure Statement}

The authors have nothing to declare.

\section{Funding Sources}

This research did not receive any specific grant from any funding agency in the public, commercial or not-for-profit sector.

\section{Author Contributions}

All the authors were actively involved in this work.

\section{References}

1 Simpson E, Santen RJ. Celebrating 75 years of oestradiol. J Mol Endocrinol. 2015 Dec;55(3):T1-20.

2 Dietel M, Lewis MA, Shapiro S. Hormone replacement therapy: pathobiological aspects of hormone-sensitive cancers in women relevant to epidemiological studies on HRT: a mini-review. Hum Reprod. 2005;20:2052-60.

3 Rossouw JE, Andersen JL, Prentice RL, LaCroix AZ, Kooperberg C, Stefanick ML, et al. Risks and benefits of estrogens plus progestin in healthy postmenopausal women: principal results from the Women's Health Initiative randomized controlled trial. JAMA. 2002;288:321-33.

4 Wharton W, Gleason CE, Miller VN, Asthana S. Rationale and design of the Kronos Early Estrogen Prevention Study (KEEPS) and the KEEPS Cognitive and Affective sub study (KEEPSCog). Brain Res. 2013 Jun 13;1514:12-7. 
Dias et al.: Is Gonadal Therapy a Promoter of Breast Cancer?

5 Mosekilde L, Hermann AP, Beck-Nielsen H, Charles P, Pars-Nielsen S, Helmer Sorensen O. The Danish Osteoporosis Prevention Study (DOPS): project design and inclusion of 2,000 normal perimenopausal women. Maturitas. 1990 March 15;31(3):207-19.

6 Venetkoski M, et al. Increased cardiac and stroke death risk in the first year after discontinuation of postmenopausal hormone therapy. Menopause. 2018 Apr;25(4):375-9.

7 The 2017 hormone therapy position statement of the North American Menopause Society. Menopause. 2017 Jul;24(7):728-53.

8 Karim R, Dell RM, Greene FD, Mack WJ, Gallagher JC, Nodis WN. Hip fracture in postmenopausal women after cessation of hormone therapy: results from a prospective study in a large health management organization. Menopause. 2011;18:1172-7.

9 Zandi PP, Carlson MC, Plassman BL, Welsh-Bohmer, Mayer LS, Steffens DC, et al. Hormone replacement therapy and incidence of Alzheimer disease in older women: the Cache county study. Cache county memory study investigators. JAMA. 2002 Nov 6;288(17):2123-9.

10 Herrera A, Nodis HN, Mack WJ, Mather M. Estradiol therapy after menopause mitigates effects of stress on cortisol and working memory. J Clin Endocrinol Metab. 2017;102(12):4457-66.

11 Beneventi F, Locatelli E, Simonetta M, Cavagnoli C, Pampuri R, Bellingeri C, et al. Vaginal development and sexual functioning in young women after stem cell transplantation, chemotherapy and/or radiotherapy for childhood hematological diseases. Bone Marrow Transpl. 2018 Sep;53(9):1157-64.

12 Angioli R, Luvero D, Armento G, Capriglione S, Plotti F, Scaletta G, et al. Hormone replacement therapy in cancer survivors: utopia? Crit Rev Oncol Hematol. 2018 Apr;124:51-60.

13 Lee JS, DuBois SG, Coccia PF, Bleyer A, Olin RL, Goldsby RE. Increased risk of second malignant neoplasms in adolescents and young adults with cancer. Cancer. 2016 Jan 1;122(1):116-23.

14 De Fine Licht S, Rugbjerg K, Gudmundsdottir T, Bonnesen TG, Asdahl PH, Holmqvist AS, et al. Long-term inpatient disease burden in the Adult Life after Childhood Cancer in Scandinavia (ALiCCS) study: a cohort study of 21,297 childhood cancer survivors. PLoS Med. 2017 May 9;14(5):e1002296.

15 Kolb HJ, Socié G, Duell T, Van Lint MT, Tichelli A, Apperley JF, et al. Malignant neoplasms in long-term survivors of bone marrow transplantation. Late effects working party of the European cooperative group for blood and marrow transplantation and the European late effect project group. Ann Intern Med. 1999 Nov 16;131(10):738-44.

16 Shiovitz S, Korde LA. Genetics of breast cancer: a topic in evolution. Ann Oncol. 2015 Jul;26(7):1291-9.

17 SOGC clinical practice guidelines. Use of hormonal replacement therapy after treatment of breast cancer. Int J Gynecol Obstet. 2005;88:216-21.

18 Rebbeck TR, Fribel T, Wagner T, Lynch HT, Garber JE, Daily MB. et al. Effect of short-term hormone replacement therapy on breast cancer risk reduction after bilateral prophylactic oophorectomy in BRCA1 and BRCA2 mutations carriers: the PROSE study group. J Clin Oncol. 2005;23:7804-10.

19 Mikkola TS, Savoilainen-Peltonen H, Tuomikoski P, Hoti F, Vattulainen P, Gissler M, et al. Lower death risk for vascular dementia than for Alzheimer's disease with postmenopausal hormone therapy users. J Clin Endocrinol Metab. 2017;102:870-7.

20 Oeffinger KC, Ford JS, Moskowitz CS, Chou JF, Henderson TO, Hudson MM, et al. Promoting Breat Cancer Surveillance: The EMPOWER Study, a Randomized Clinical Trial in the Childhood Cancer Survial Study. J Clin Oncol. 2019 Aug 20;37(24):2131-40.

21 Danylesko I, Shimoni A. Second malignancies after hematopoietic stem cell transplantation. Curr Treat Options Oncol. 2018 Feb 8;19(2):9.

22 Demoor-Goldschmidt C, Supiot S, Mahé MA, Oberlin O, Allodji R, Haddy N, et al. Clinical and histological features of second breast cancers following radiotherapy for childhood and young adult malignancy. $\mathrm{Br} \mathrm{J}$ Radiol. 2018 Jun;91(1086):20170824.

23 Naghavi M. The global burden of cancer 2013. JAMA Oncol. 2015 Jul 1;1(4):505-27.

24 Collaborative Group on Hormonal Factors in Breast Cancer. Breast cancer and hormone replacement therapy: collaborative reanalysis of data from 51 epidemiological studies of 52,705 women with breast cancer and 108,411 women without breast cancer. Lancet. 1997 Oct 11;350(9084):1047-59. Erratum in: Lancet 1997 Nov 15;350 (9089):1484

25 Espié M, Daures JP, Chevallier T, Mares P, Micheletti MC, De Reilhac P. Breast cancer incidence and hormone replacement therapy: results from the MISSION study, prospective phase. Gynecol Endocrinol. 2007 Jul;23(7):391-7.

26 Misra M. Effects of hypogonadism on bone metabolism in female adolescents and young adults. Nat Rev Endocrinol. 2012;8:395-404.

27 Lobo RA. Where are we 10 years after the women's health initiative? J Clin Endocrinol Metab. 2013;98(5):1771-80.

28 Wang Y, Wactawski-Wende J, Sucheston-Campbell LE, Preus L, Hovey KM, Nie J, et al. Gene-hormone therapy interaction and fracture risk in postmenopausal women. J Clin Endocrinol Metab. 2017;102(6):1908-16.

29 Papadakis GE, Hans D, Rodriguez EG, Vollenweider P, Waeber G, Maeques-Vidal P, et al. Menopausal hormone therapy is associated with reduced total and visceral adiposity: the OsteoLaus Cohort. J Clin Endocrinol Metab. 2018;103(5):1948-57.

30 Lobo R. Don't be so quick to stop hormone-replacement therapy. Nat Rev Endocrinol. 2016 Jan;12(1):11-3.

31 Faubion SS, Kuhle CL, Shuster LT, Rocca WA. Long-term health consequences of premature or early menopause and considerations for management. Climacteric. 2015;18(4):483-91. 